Ann. Parasitol. Hum. Comp., 1991, $66: \mathrm{n}^{\circ} 1,3-8$.

Mémoire.
Key-words: Trypanosoma cruzi. Columbia. Morphometry. Variance analysis.

Mots-clés : Trypanosoma cruzi. Colombie. Morphométrie. Analyse de la variance.

\title{
THE APPLICATION OF THE STATISTICAL STUDY IN THE MORPHOMETRIC CHARACTERIZATION OF A COLOMBIAN STRAIN OF TRYPANOSOMA CRUZI
}

\author{
J. A. DE DIEGO*, P. PENIN*, F. MAYER*, J. DELREY**, \\ C. GAMALLO***
}

\begin{abstract}
SUMMARY
After morphological and histopathological characterization, the Cali strain of $T$. cruzi isolated from a patient in Cali (Colombia), was also submitted to a morphometrical characterization. For this we estimated 16 cellular parameters in 30 samples of each evolutive form of $T$. cruzi in blood in NNN medium through planimetry by the IBAS-1 (Image Basic Analytic System).

This morphometrical study was completed with a statistical one

through the application of the variance (ANOVA-1). This made it possible to evidence a great number of significant differences between the slender, broad and stout forms and also between the short and large epimastigotes from the NNN medium. These data have a real interest for classifying some features of the biological cycle of $T$. cruzi as well as the future development of diagnosis techniques or therapeutical and prophylactic experiments.
\end{abstract}

RÉsumé : Utilisation de l'étude statistique pour la caractérisation morphométrique d'une souche colombienne de Trypanosoma cruzi.

Après avoir effectué la caractérisation morphologique et histopathologique de la souche Cali de $T$. cruzi, isolée d'un patient dans la ville de Cali (Colombie), nous avons réalisé sa caractérisation morphométrique. Dans ce but, nous avons effectué des mesures concernant 16 paramètres cellulaires dans 30 échantillons de chaque forme évolutive de $T$. cruzi dans le sang et le milieu de culture NNN à l'aide de la planimétrie réalisée avec l'autoanalyseur d'images (IBAS-1).

L'étude morphométrique a été complétée par une autre étude statistique utilisant l'application de la variance (ANOVA-1). Ceci nous a permis de constater l'existence d'un grand nombre de différences quantitatives entre les formes slender, broad et stout, ainsi qu'entre les formes épimastigotes courtes et larges du milieu NNN. L'intérêt de l'étude est de permettre une meilleure interprétation du cycle biologique de $T$. cruzi et de faciliter le développement de futures techniques de diagnostic et des essais thérapeutiques ou prophylactiques.

\section{INTRODUCTION}

Morphologic conventional studies were used in order to characterize the strains of T. cruzi (Brener and Chiari, 1963 and Andrade, 1974). In this study we realized a morphological study using the plane surveying (planimetry) in order to establish if some parameters of $T$. cruzi are able to contribute with new data to the conventional morphology making possible a better characterization of isolated strains from distinct geographical areas.

We were also interested in establishing the existence of other parameters (except those established by conventional

* Unidad de Parasitologia, Dpto. de Medicina Preventiva y Salud Pública, Facultad de Medicina de la Universidad Autónoma de Madrid, c. Arzobíspo Morcillo n 4, 28029 Madrid, España.

** Director del Dpto. de Medicina Preventiva y Salud Pública, Facultad de Medicina de la Universidad Autónoma de Madrid, Madrid, España.

*** Dpto. de Anatomía Patologicá, CSSS, « La Paz », Madrid, España.

Accepté le : 14 mars 1991. microscopy) able to give more information about the differences between the evolutive forms of a strain.

The posterior application of the statistical analysis gave us the possibility to establish the existence of significant differences between the same parameters of distinct evolutive forms of $T$. cruzi which may help to a better comprehension of its biological cycle.

Moreover, the application of the statistical method to the morphometrical values will permit a comparison between various strains of the parasite establishing the most important parameters in their differentiation through the study of the significant differences between the above mentioned parameters.

\section{MATERIAL AND METHODS}

I $-T$. cruzi STRAIN

The Cali strain isolated from a patient in Cali (Colombia) in 1968, fetched at the laboratory of Parasitology of the Faculty of Medicine: Autonom University of Madrid in February 1970. The strain was morphologically and histopathologically characte- 
rized by ourselves (submitted) and maintained in our Laboratory through passages in mice.

\section{II - ANIMAls uSEd IN THE EXPERIMENT}

The mice Mus musculus of the strain Swiss Ico $\left(\mathrm{OF}_{1}\right.$; IOPS Caw) are maintained in the Animalarium of the Medicine Faculty (UAM) in the following conditions:

Photoperiodicity: 12 hours light/12 hours dark.

Temperature: $\quad 21 \pm 1^{\circ} \mathrm{C}$.

Humidity: $\quad 55 \pm 10 \%$.

Air removal: Ten to fifteen changes/hour.

\section{III - Morphological STUdy}

a) Preparation of the material

- Lantern slides of the different forms of the biological cycle were realized as follows;

- Forms of the NNN medium (Brack, 1968; Hoare, 1972 and Brener, 1973);

- Sphaeromastigotes: rounded forms possessing a free flagellum;

- Epimastigotes: elongated forms with juxtanuclear kinetoplast and flagellum arising near it. There are short epimastigotes which measuring 10-20 $\mu \mathrm{m}$ and long epimastigotes measuring $35-40 \mu \mathrm{m}$;

- Metacyclic trypomastigotes: represented by elongated forms with a postnuclear kinetoplast; flagellum arising near it and emerging from the side of the body to run along an undulating membrane;

- Blood forms (Brener and Chiari, 1963). Essentially these forms are like the metacyclic trypomastigote forms, but we can differ between:

. Slender: thin forms with kinetoplast a distance from the posterior end. The nucleus being medial and lengthen,

. Stout: very wide forms with terminal or subterminal kinetoplast. The nucleus being rounded and the cytoplasm vacuolated,

. Broad: these are no thin nor stout forms. The kinetoplast is located in terminal or subterminal position. Rounded nucleus medial or anterior.

Thirty slides for each above mentioned forms were realized and their images were enlarged by drawings in an Image Amplifier Leitz Wetzlar of the type Prado Universal. The projection scale was of $1: 2,5 / 90 \mathrm{~mm}$.

b) MORPHOMETRY THROUGH THE IBAS-I (Image Basic Analytic System). In order to measure the drawning forms by this method

\section{TABLE I. - Legend of the used morphometric parameters.}

L : Total body length (including free flagellum).

$\mathrm{F}$ : Length of the free flagellum.

NP : Distance between the nucleus and the posterior extremity.

NA : Distance between the nucleus and the anterior extremity.

AN : Nuclear surface.

PN : Nuclear perimeter.

AC : Cytoplasmic surface.

PC : Cytoplasmic perimeter.

AK : Kinetoplast surface.

PK : Kinetoplast perimeter.

A : Cellular wide.

NK : Distance between the nucleus and the kinetoplast.

N/C : Relation nucleus/cytoplasm.

IN : Nuclear index.

LC : Cytoplasmatic length.

F/C : Relation flagellum/cytoplasm. we used the IBAS-1 which permit the planning surveying made by an incorporated tracer to the digital drawing board which is passing over the selected structures of the drawing at the scale of which it was submitted.

The measured parameters ar communicated in Table I.

\section{c) Statistical study}

- Subjects: The different forms of the Cali strain of $T$. cruzi from blood and NNN medium were studied as we expose in the a) point.

- Procedure: Thirty subjects of each mentioned forms were measured, and the values of sixteen parameters for each form were studied through the plane surveying with the IBAS-1. These data were processed in an AT Computer. The statistical programme BMDP was used and the variation 7D which permits the description of the groups in layers and the analysis of the variety was selected.

- Design: Data programme: in each line we include a number corresponding to each case. In continuation, we marked the codes of the independent variants of our study: the form and the medium in which it was studied. In order to simplify the analysis we reach to obtain with the same code a simultaneous information about the form and the medium. Then, we placed the corresponding data to dependent variants which are reflected in the Table I reproducing the obtained values for the 16 morphometric parameters measured by the IBAS-1.

In this manner, each concrete case remained well defined by the codes corresponding to the number, the independent variant form-medium and the 16 dependent variants above mentioned. The successive order is always the same and each value was occupying in all the cases the same number of bytes.

The control variants in our paper were the temperature and the degree of relative humidity in the case of the NNN culture. In the rodent model we added the air removal and the periodical changes of the night.

By this manner we obtained a file of 210 lines.

Instructions programme: These programmes made possible the realization by the BMDP of the Analysis of the variability according to our data programme.

The large and short epimastigotes from the NNN medium were compared. In the blood, the comparisons were slender/broad, slender/stout and broad/stout. For this we used 64 instructionprogrammes. In each of the compared cases we were starting from the null hypothesis $\mathrm{H}_{0}=\mathrm{X}_{1}=\mathrm{X}_{2}$, which is equivalent to consider that there are no significant differences for each concrete parameter among the measures of the thirty studies cases in the two compared groups. For this null hypothesis, there is an alternative: $\mathrm{H}_{1}=\mathrm{X}_{1} \neq \mathrm{X}_{2}$.

In our study we have considered as a level of significance $p \leq 0.05$. In order to analyze the value of the null hypothesis in each dependent variant (morphometric parameter) we used in each concrete case an analysis of the variance of the type ANOVA-1.

The compared forms are always presenting the same number of 30 cases. So that we compared the average of thirty cases with that of other thirty different cases.

\section{RESULTS}

\section{I - MORPHOMETRICAL STUDY OF THE BLOOD FORMS of THE CALI STRAIN}

The comparison between the slender and broad forms of this strain shows significant differences in the majority 
TABLE II. - T. cruzi (Cali strain): morphometry (in $\mu \mathrm{m}$ ) of the blood forms.

\begin{tabular}{|c|c|c|c|c|c|c|c|c|c|}
\hline \multirow{2}{*}{$\begin{array}{c}\text { Studied } \\
\text { parameters }\end{array}$} & \multicolumn{3}{|c|}{ Slender } & \multicolumn{3}{|c|}{ Broad } & \multicolumn{3}{|c|}{ Stout } \\
\hline & $\bar{X}$ & $S D$ & $\mathrm{Sm}$ & $\bar{X}$ & $S D$ & $S m$ & $\bar{X}$ & $S D$ & $S m$ \\
\hline $\mathrm{L}$ & 26.38 & 5.17 & 2.58 & 31.02 & 5.48 & 1.00 & 30.60 & 3.92 & 0.71 \\
\hline $\mathrm{F}$ & 8.38 & 3.22 & 1.61 & 10.10 & 2.56 & 0.46 & 9.31 & 1.58 & 0.28 \\
\hline NP & 17.88 & 10.88 & 5.44 & 12.27 & 2.22 & 0.40 & 12.47 & 2.67 & 0.48 \\
\hline NA & 10.83 & 4.80 & 2.40 & 8.72 & 3.06 & 0.55 & 8.95 & 2.23 & 0.40 \\
\hline AN & 4.75 & 2.23 & 1.11 & 4.16 & 1.33 & 0.24 & 4.91 & 1.10 & 0.20 \\
\hline PN & 10.37 & 2.39 & 1.19 & 8.06 & 1.21 & 0.22 & 8.65 & 1.22 & 0.22 \\
\hline $\mathrm{AC}$ & 25.19 & 9.73 & 4.86 & 27.25 & 9.13 & 1.66 & 45.16 & 9.18 & 1.67 \\
\hline PC & 33.26 & 5.54 & 2.77 & 34.18 & 4.67 & 0.85 & 34.36 & 4.20 & 0.76 \\
\hline $\mathrm{AK}$ & 1.66 & 0.64 & 0.32 & 1.94 & 0.46 & 0.08 & 2.10 & 7.16 & 0.13 \\
\hline $\mathrm{PK}$ & 4.75 & 0.93 & 0.46 & 7.49 & 12.65 & 2.31 & 5.26 & 0.97 & 0.17 \\
\hline A & 1.55 & 0.43 & 0.21 & 2.46 & 0.35 & 0.06 & 5.22 & 1.06 & 0.19 \\
\hline NK & 10.12 & 3.25 & 1.62 & 10.23 & 1.82 & 0.33 & 11.34 & 2.41 & 0.44 \\
\hline $\mathrm{N} / \mathrm{C}$ & 0.18 & 0.02 & 0.01 & 0.16 & 0.06 & 0.01 & 0.11 & 0.02 & 0.00 \\
\hline IN & 1.86 & 1.31 & 0.65 & 1.56 & 0.55 & 0.10 & 1.50 & 0.58 & 0.10 \\
\hline $\mathrm{LC}$ & 18.00 & 2.93 & 1.46 & 20.90 & 3.78 & 0.69 & 21.28 & 3.26 & 0.59 \\
\hline $\mathrm{F} / \mathrm{C}$ & 0.46 & 0.17 & 0.08 & 0.48 & 0.10 & 0.01 & 0.44 & 0.09 & 0.01 \\
\hline
\end{tabular}

TABLE III. - T. cruzi: analysis of the variance of morphometric blood parameters in the Cali strain.

\begin{tabular}{llll}
\hline $\begin{array}{c}\text { Studied } \\
\text { parameters }\end{array}$ & $\begin{array}{c}\text { Slender } \\
\text { versus broad }\end{array}$ & $\begin{array}{c}\text { Slender } \\
\text { versus } \text { stout }\end{array}$ & $\begin{array}{c}\text { Broad } \\
\text { versus } \text { stout }\end{array}$ \\
\hline L & $p=0.00$ & $p=0.00$ & $p=0.77$ \\
F & $p=0.00$ & $p=0.00$ & $p=0.16$ \\
NP & $p=0.00$ & $p=0.00$ & $p=0.83$ \\
NA & $p=0.00$ & $p=0.00$ & $p=0.74$ \\
AN & $p=0.04$ & $p=0.50$ & $p=0.02$ \\
PN & $p=0.00$ & $p=0.00$ & $p=0.07$ \\
AC & $p=0.02$ & $p=0.00$ & $p=0.00$ \\
PC & $p=0.53$ & $p=0.19$ & $p=0.68$ \\
AK & $p=0.00$ & $p=0.00$ & $p=0.09$ \\
PK & $p=0.00$ & $p=0.00$ & $p=0.74$ \\
A & $p=0.00$ & $p=0.00$ & $p=0.00$ \\
NK & $p=0.77$ & $p=0.01$ & $p=0.04$ \\
N/C & $p=0.17$ & $p=0.00$ & $p=0.00$ \\
IN & $p=0.02$ & $p=0.05$ & $p=0.64$ \\
LC & $p=0.00$ & $p=0.00$ & $p=0.69$ \\
F/C & $p=0.24$ & $p=0.43$ & $p=0.11$ \\
\hline
\end{tabular}

of measured parameters, being the error probability of 0.00 for the total length, the length of the flagellum and the cytoplasm. These three parameters are greater in the broad forms.

Concerning the slender forms we observed that the nucleus is situated in a more anterior position than in the broad ones and this difference is also statistically significant if we consider the values of posteronuclear measures and nuclear indices. The cynetoplastic area and its perimeter as well as the cell width are statistically different, being the measures greater than in the broad forms.

If we observe the obtained data through the comparison of slender and stout forms we can see a great number of significant differences.
This is obvious because the two compared forms can be easily differentiated with the conventional techniques. However, we consider to comment also the non significant parameters namely the nuclear area, the cytoplasmic area and the relation flagellum/cytoplasm.

The comparative study of the broad and stout forms gave few significant differences. These were visible in the nuclear and cytoplasmic areas and the cellular width being greater in the stout forms.

The broad forms have a nucleus proportionally greater in relation with the cytoplasm. The commented data are reflected in Tables $I I$ and $I I I$.

\section{II - MORPHOMETRIC STUDY IN THE FORMS OF THE NNN MEDIUM}

The large epimastigotes were the greatest from all the forms of $T$. cruzi cycle in this strain. The average of the total length of the measured forms was of $40.67 \mu \mathrm{m}$. The metacyclic forms were the shorter ones: $23,87 \mu \mathrm{m}$. The differences in total length are fundamentally visible in relation with the cytoplasmic length.

The short epimastigotes as well as the large ones are presenting a nucleus which is situated practically in the middle of these forms. The metacyclic forms showed a nucleus clearly located in the anterior part of the body.

The nuclear area was greater in the sphaeromastigotes, followed by large epimastigotes and metacyclic forms. However, the nuclear perimeter of the last ones was the double of the other forms from the NNN medium. The kinetoplastic area was greater in the spheromastigotes, being the smallest in the short epimastigotes.

As we can see in the optic microscope, the distance between the nucleus and the kinetoplast is very little in the 
TABLE IV. - T. cruzi (Cali strain): morphometry (in $\mu m$ ) of the NNN culture forms.

\begin{tabular}{|c|c|c|c|c|c|c|c|c|c|c|c|c|}
\hline \multirow{2}{*}{$\begin{array}{c}\text { Studied } \\
\text { parameters }\end{array}$} & \multicolumn{3}{|c|}{ Short epimastigotes } & \multicolumn{3}{|c|}{ Large epimastigotes } & \multicolumn{3}{|c|}{ Sphaeromastigotes } & \multicolumn{3}{|c|}{ Metacyclic } \\
\hline & $\bar{X}$ & $S D$ & $S m$ & $\bar{X}$ & $S D$ & $S m$ & $\bar{X}$ & $S D$ & $S m$ & $\bar{X}$ & $S D$ & $S m$ \\
\hline $\mathrm{L}$ & 25.84 & 6.76 & 1.23 & 40.67 & 26.20 & 1.13 & 26.06 & 4.45 & 0.81 & 23.86 & 2.97 & 0.54 \\
\hline$F$ & 14.06 & 6.02 & 1.10 & 17.86 & 4.66 & 0.85 & 15.50 & 3.90 & 0.71 & 8.86 & 2.95 & 0.54 \\
\hline NP & 5.82 & 1.86 & 0.34 & 10.93 & 3.25 & 0.59 & 4.15 & 2.82 & 0.51 & 9.66 & 4.50 & 0.27 \\
\hline NA & 5.99 & 2.67 & 0.48 & 11.89 & 4.68 & 0.85 & 6.58 & 3.02 & 0.55 & 5.42 & 1.25 & 0.22 \\
\hline AN & 3.38 & 0.86 & 0.15 & 4.11 & 1.49 & 0.27 & 5.52 & 3.00 & 0.54 & 3.76 & 0.84 & 0.15 \\
\hline PN & 6.83 & 0.94 & 0.17 & 7.65 & 1.63 & 0.29 & 8.75 & 2.46 & 0.44 & 9.62 & 1.71 & 0.31 \\
\hline $\mathrm{AC}$ & 16.85 & 5.87 & 1.07 & 37.28 & 15.67 & 2.86 & 29.25 & 8.98 & 1.63 & 13.02 & 3.10 & 0.56 \\
\hline PC & 23.29 & 7.11 & 1.29 & 44.60 & 12.01 & 2.19 & 20.80 & 3.88 & 0.70 & 28.65 & 3.91 & 0.71 \\
\hline $\mathrm{AK}$ & 1.61 & 0.44 & 0.08 & 1.88 & 0.53 & 0.09 & 2.59 & 1.12 & 0.20 & 1.39 & 0.40 & 0.07 \\
\hline PK & 4.92 & 1.22 & 0.22 & 5.13 & 0.82 & 0.14 & 6.69 & 2.51 & 0.45 & 4.32 & 0.65 & 0.11 \\
\hline A & 2.39 & 0.45 & 0.08 & 2.46 & 0.53 & 0.10 & 5.45 & 1.12 & 0.20 & 1.46 & 0.27 & 0.05 \\
\hline NK & 2.00 & 0.44 & 0.08 & 2.37 & 0.73 & 0.13 & 3.72 & 1.72 & 0.31 & 5.85 & 1.54 & 0.28 \\
\hline $\mathrm{N} / \mathrm{C}$ & 0.21 & 0.07 & 0.01 & 0.11 & 0.03 & 0.00 & 0.18 & 0.07 & 0.01 & 0.29 & 0.08 & 0.01 \\
\hline IN & 1.15 & 0.79 & 0.14 & 1.14 & 0.74 & 0.13 & 1.01 & 1.02 & 0.18 & 1.90 & 0.65 & 0.11 \\
\hline LC & 11.78 & 3.75 & 0.68 & 22.80 & 6.06 & 1.10 & 10.55 & 2.06 & 0.37 & 14.99 & 1.77 & 0.32 \\
\hline F/C & 1.32 & 0.77 & 0.14 & 0.87 & 0.44 & 0.08 & 1.51 & 0.48 & 0.09 & 0.60 & 0.24 & 0.04 \\
\hline
\end{tabular}

TABLE V. - T. cruzi (Cali strain): analysis of the variance of morphometric parameters between the epimastigote forms in the NNN culture.

\begin{tabular}{cc}
\hline Studied & $\begin{array}{c}\text { Large epimastigote } \\
\text { versus } \\
\text { parameters }\end{array}$ \\
short epimastigote \\
\hline L & $p=0.00$ \\
F & $p=0.00$ \\
NP & $p=0.00$ \\
NA & $p=0.00$ \\
AN & $p=0.02$ \\
PN & $p=0.02$ \\
AC & $p=0.00$ \\
PC & $p=0.00$ \\
AK & $p=0.63$ \\
PK & $p=0.04$ \\
A & $p=0.57$ \\
NK & $p=0.02$ \\
N/C & $p=0.00$ \\
IN & $p=0.95$ \\
LC & $p=0.00$ \\
F/C & $p=0.00$ \\
\hline
\end{tabular}

epimastigotes, being minimal in the short ones. The width of the spheromastigotes is greater than in the other remaining observed forms. The thinest of all were the metacyclic trypomastigotes. In these forms, the relation nucleus/cytoplasm is very high. The mentioned above data can be observed in Table IV.

The statistical analysis concerning the forms in the NNN medium was realized comparing the short and large epimastigotes. The majority of the parameters were presenting significant differences except the kinetoplastic area, the width and the nuclear index. All the significant parameters were at the expense of a greater value for the large epimastigotes except the relations nucleus/cytoplasm and flagellum/cytoplasm which are greater in the short epimastigotes.

These data are detailed in Table $V$.

\section{DISCUSSION}

A striking feature of this parasite is its extreme heterogeneity with respect to biochemical, medical and other biological properties (Dvorak, 1984; Brénière et al., 1985; Tibayrenc et al., 1986 and Tibayrenc and Ayala, 1988). Various methods have been used or proposed for the characterization of $T$. cruzi fine structure of the kinetoplast as revealed by electron microscopy (Mühlpfordt, 1975), zymodeme analysis (Miles, 1979), buoyant density determination by nuclear and kinetoplast DNA (kDNA) (Baket et al., 1978), restriction endonuclease fingerprinting of kDNA (Brack et al., 1976 and Mattei et al., 1977), agglutination reactions by lectins (Schlemper and Schottelius, 1979), etc.

Most of them failed to reveal differences among strains or to relate these data with the different behavior patterns (Tibayrenc et al., 1983). The genotype characterization by restriction endonuclease fingerprinting of kinetoplast DNA minicircles (Morel and Simpson, 1980 and Morel et al., 1980) seems to be the most promising method. Unfortunately, this method is in general rather limited by the costly equipment and specialized techniques needed.

We propose the use of a method of morphometry to distinguish between different forms of the $T$. cruzi life cycle. By this method we could perform strain typification. To know if the differences between two $T$. cruzi forms are due at random we use the study of the variance with a significance level of $p \leq 0.005$. 
The analytic morphometry allowed us to observe the existence of a great number of parameters with significatives differences in the distinct evolutive forms of a given $T$. cruzi strain. It was our intention to compare the evolutive forms in the cases in which the morphometry may produce an enrichment in the obtained data by conventional morphology. It deals with the blood forms compared among them and the short and large epimastigotes.

It is well known that animals inoculated with strains showing predominantly stout or slender forms present different patterns which prevailed after many years (Brener, 1973). We have thought that these patterns of behavior could be related with some morphometrical parameter. So that we have studied the significatives differences between the blood forms of the Cali strain. The stout forms showed the highest nuclear surface in comparison with other blood forms. Maria et al., (1972) claimed that the variations of this parameter observed by the electronic microscope were non significant between the slender, broad and stout forms, emphasizing the lack of correlation of that similitude with the physiological differences which are observed between in three forms. However, in our study we were able to establish a morphological basis which is related to such functional difference.

Maria et al. (1972) reported a higher mitochondrial surface of the stout forms which was confirmed by us comparing the kinetoplastic areas of the distinct blood forms closely connected with the mitochondria.

Vickerman (1974) stated that the greatest size of the kinetoplast may be due to its polyenergetical character. Wallace (1966) has emphasized the importance of this structure in the survival of $T$. cruzi.

In our study the slender forms shows a nucleus located in a more anterior position than in the broad forms. Hoare (1972) stated that $T$. brucei has the nucleus usually located in the posterior part of the cell. It is possible that this character may be related to the pathogenic capacity of these forms.

The different forms founded in the NNN culture have also different behavior. It is specially interesting to see the difference existing between th short and long epimastigote forms. The short epimastigotes have capacity to multiply intensively or to differentiate into long epimastigote forms. Long epimastigote can differentiate into infective, metacyclic trypomastigotes. The statistical study applied to the comparison between short and large epimastigotes from the NNN medium shows that their difference is not due only to the cellular length, the majority of the measured parameters were presenting significant differences. One of the most obvious was the difference concerning the distance between the nucleus and the kinetoplast which is smaller in the short epimastigotes. Considering that the differentiation of $T$. cruzi toward the metacyclic forms occurs through the progressive movement of the kineto- plast in the direction of the posterior extremity of the parasite (Sanabria, 1966 and Dvorak, 1976) we are considering the possibility of an evolution of the large epimastigotes from the short ones.

We are also emphasizing that the large epimastigotes was greater, suggesting a major activity of them.

\section{REFERENCES}

Andrade S. G. : Caracterização de cepas do Trypanosoma cruzi isoladas no Reconcavo Baiano. Rev. Pat. Trop., 1974, 1, 65-121.

Baker J. R., Miles M. A., Godfrey D. G., Barret T. V. : Biochemical characterization of some species of Trypanosoma (Schizotrypanum) from bats (Microchiroptera). Am. J. Trop. Med. Hyg., 1978, 27, 483-487.

Brack C. : Electroenmikroskopische untersochungen zum lebenszyklus von Trypanosoma cruzi. Acta tropica, 1968, 25, 289-356.

Brack C., Bickle T. A., Yuan R., Barker D. C., Foulkes M., Newton B. A., Jenni L. : The use of restriction endonucleases for the investigation of kinetoplast DNA. In: Biochemistry of parasites and Host-Parasites Relationships $(\mathrm{H}$. Van den Bossche, ed.). Elsevier/North Holland Biomedical Press, Amsterdam, 1976, 211-218.

Brener Z., Chiari E. : Variaçōes morfológicas observadas em diferentes amostras de Trypanozoma cruzi. Rev. Inst. Trop. Sâo Paulo, 1963, 5, 220-224.

Brener Z. : Biology of Trypanosoma cruzi. Ann. Rev. Microbiol., 1973, 27, 347-382.

Brénière S. F., Tibayrenc M., Atenzana G., Pabón J., Carrasco R., Selaès H., Desjeux P. : Résultats préliminaires en faveur d'une relation faible ou inexistante entre les formes cliniques de la maladie de Chagas et les souches isoenzymatiques de Trypanosoma cruzi. C. R. Acad. Sci. Paris, 1985, 300, 555-557.

Dvorak J. A. : New in vitro approach to quantitation of Trypanosome cruzi-vertebrate cell interactions. In: American Trypanosomiasis Research. WHO Sci. Publ., $n^{\circ} 318$, Washington, 1976, 109-120.

Dvorak J. A. : The natural heterogeneity of Trypanozoma cruzi: biological and medical implications. J. Cell. Biochem., 1984, 24, 357-371.

Hoare C. A. : The stercoraria subgenus Schyzotrypanum Chagas, 1909. In: The trypanosomes of mammals. A zoological monograph. BSP, Oxford-Edinburg, 1972, 360-380.

Maria T. A., Tafuri W., Brener Z. : The fine structure of different blood stream forms of Trypanosoma cruzi. Ann. Trop. Med. Parasitol., 1972, 66, 423-431.

Mattei D. M., Goldenberg S., Morel C., Azevedo H. P., Roitman I. : Biochemical strain characterization of Trypanosoma cruzi by restriction endonuclease cleavage of Kinetoplast DNA. FEBS Letters, 1977, 74, 264-268.

Miles M. A. : Transmission cycles and the heterogeneity of Trypanosoma cruzi. In: WHR Biology of the Kinetoplastida. Vol. 2. (Lumsden and Evans, eds.). Academic Press, London and New York, 1979, 117-196.

Morel C., Simpson L. : Characterization of pathogenic trypanosomatidae by restriction endonuclease fingerprinting of Kinetoplast DNA Minicircles. Am. J. Trop. Med. Hyg., 1980, 29, 1070-1074.

Morel C., Chiari E., Plessmann Camargo E., Mattei D. M., Romanha A. J., Simpson L. : Strains and clones of Trypanosoma cruzi can be characterized by pattern of restriction endonuclease products if kinetoplast DNA minicircles. Proc. Natl. Acad. Sci. USA, 1980, 77, 6810-6814. 
Mühlpfordt H. : Vergleichende Kinetoplast morphologie verschiedener Trypanosomenarten unter besonderer BerUurcksichtigung von Trypanosoma cruzi. Tropemed. Parasitol., 1975, 26, 239246.

Sanabria A. : Ultrastructure of Trypanosoma cruzi in the rectum of Rhodnius prolixus. Exp. Parasitol., 1966, 19, 276-299.

Schlemper B. R., Jr., Schottelius J. : Comparative study of Trypanosoma cruzi strains from two geographical areas. II. Study with lectins. Congresso Internacional sobre Doença de Chagas. Proceedings of an International Symposium, Rio de Janeiro, Brazil, 1979, July 22-28, p. 35. Fundaçao Oswaldo Cruz, Rio de Janeiro, RJ Brazil.

Tibayrenc M., Echalar L., Brénière F., Lemesre J. L., Barnabé C. H., Desjeux P. : Sur le statut taxonomique et médical des souches isoenzymatiques de Trypanosoma cruzi, considérations sur la valeur systématique et immunogénique des différentes isoenzyme profiles and further arguments against Mendelian sexuality. Trans. Roy. Soc. Trop. Med. Hyg., 1983, 78, 519-524.

Tibayrenc M., Ward A., Moya A., Ayala F. J. : Natural populations of Trypanosoma cruzi, the agent of Chaga's disease, have a complex multiclonal structure. Proc. Nat. Acad. Sci. USA, $1986,83,115-119$.

Tibayrenc M., Ayala F. J. : Isozyme variability in Trypanosoma cruzi, the agent of Chaga's disease: genetical, taxonomical and epidemiological significance. Evolution, 1988, 42, 277-292.

Vickerman K. : The ultrastructure of pathogenic flagellates. In: Trypanosomiasis y leishmaniasis. Ciba Foundation Symposia, 1974, 171-190.

Wallace F. G. : The trypanosomatid parasites of insects and arachnids. Exp. Parasitol., 1966, 18, 124-193. 